\title{
Geographic Aspects of Integration of Ecological and Economic Systems
}

\author{
Malyshev A.A. \\ Penza State Technological University \\ Penza, Russia \\ malyshe-aleksej@yandex.ru
}

\author{
Solodkov N.N. \\ Penza State University of Architecture and Construction \\ Penza, Russia \\ niconsol@yandex.ru
}

\author{
Patturi Ya.V. \\ Yaroslav-the-Wise Novgorod State University \\ Veliky Novgorod, Russia \\ Yanina.Patturi@novsu.ru
}

\begin{abstract}
Modern solutions to economic problems require a systematic approach that covers the social and ecological aspects of management. In this regard, the ecological and economic approach is becoming widespread in the practice of making management decisions. In this case, the object of management is ecological and economic systems. The authors of the article consider them as geographically separate historically formed natural and anthropogenic formations, structurally and functionally organized, formed with the participation and under the influence of a man in order to meet his needs. The interaction of ecological and economic systems through the communication of flows, energy and information leads to their integration. The substance flow consists of two main components: final product and waste. On the example of the administrative-territorial districts of Penza region of the Russian Federation, the substance flow is analyzed using the ratio of trade turnover to the cost of disposal expenditures for the waste remaining after recycling. As a result, three main groups of districts were identified: with a low cost of residual waste disposal to trade turnover; with a coefficient close to "zero"; with a high transit function of ecological and economic systems. A decrease in expenses for residual waste recycling was noted in agricultural districts and transit districts. The article was prepared within the framework of the grant of the Russian Foundation for Basic Research No. 20-010-00875 A "Problems of managing sustainable socio-ecological and economic development of Russia and ways to solve them".
\end{abstract}

Keywords-ecological and economic systems, economic geography, socio-economic integration.

\section{INTRODUCTION}

The ecological and economic approach to the management of natural and anthropogenic systems has been used for a long time (since about the mid-1950s). Its goal is to preserve and increase the natural wealth and diversity of geosystems combined with the growth of well-being and prosperity of the population. In Russia, it is just getting its distribution and is being introduced into economic circulation.
The dominant approach to understanding ecological and economic systems is ecological, i.e. as a part of the ecosphere [1]. The object of research is the state of nature as a human and social habitat [2]. The health, well-being and development of the population depends entirely on the quality of the environment. In this regard, ecological and economic systems are an environment-forming complex of interacting components that is organized by human economic activities. Actually existing in space, they interact with each other on their borders - they integrate. There are sharp or gradual transitions from one economic dominant to another. Therefore, ecological and economic systems are understood as geographically separate historically formed natural and anthropogenic formations, structurally and functionally organized, formed with the participation and under the influence of a man in order to meet his needs.

The structural organization of ecological and economic systems can be vertical and horizontal. The vertical structure is determined by the component composition of the main environments: ecological, social, institutional, and economic. Then the most important types of connections are distinguished: economic and ecological, ecological, ecological and economic, socio-economic, economic, social, socio-ecological and institutional [3]. The horizontal structure is due to uneven distribution of energy, substance and information. In the works of B. Fu et al. [4], Q. Gao et al. [5], C. Cavalcanti [6] it is noted that this set is typical only for natural systems. However, the natural circulation is changed by the economic activities waste, being filled with certain chemicals that are not characteristic for natural systems [7]. There is an influx of energy lost during its production. For example, in cooling ponds of thermal power station.

The horizontal structure of ecological and economic systems is generally considered at five main levels [7]: planetary, national, regional, local, and enterprise-wide. 
The boundaries are generally administrative [8]. From the perspective of the genetic approach this statement becomes not so unambiguous and requires clarification and development: within administrative borders, complex historically formed ecological and economic systems are generally enclosed.

Substance, energy and information flows circulate inside the ecological and economic systems and migrate along major transport routes [9]. These are highways, pipelines, air services, water and rail transport, as well as communications. Such a flow is a part of the territorial organization of social production. However, the expenditure part is not considered in this flow waste. It arises at the stage of raw material extraction (sludge during mining), production (waste from industrial zones), transportation (along transport routes), consumption and disposal.

Waste partially settles during migration from one ecological and economic system to another and accumulates in reservoirs, atmosphere and soil [10]. The latter component can be considered as a product not only of natural complexes, but also of ecological and economic systems. The soil accumulates inert compounds and chemical elements (for example, the accumulation of copper, lead, and zinc indicates the development of metallurgy [11], and migrating compounds accumulate at a remote distance from the main source of pollution).

The integration of ecological and economic systems is based on the ratio of the commodity flow cost to the expenses on residual waste disposal. The commodity flow consists of the difference between the cost of products, goods and services produced in a given territory and the cost of imports. A positive balance indicates the export component of the substance, energy and information transferred to other ecological and economic systems. Ecology and economic systems with a negative commodity balance accept final products and intermediate products, which are further processed and consumed in it.

The positive coefficient of the ratio of the commodity flow to the cost of residual waste disposal reflects the low cost of their recycling. The small amount of unprocessed waste remainder may be due to either underestimating the mass of waste (for example, in agricultural areas), or to the low cost of waste recycling. The transfer of substance, energy and information from ecological and economic systems is indicated.

The negative coefficient of the ratio of the commodity flow to the cost of residual waste disposal characterizes the influx of final and intermediate products from other ecological and economic systems. An additional input of products is indicated, which constitutes an increase in waste during the consumption or recycling (its accumulation).

The value of the ratio of the commodity flow to the cost of residual waste disposal close to "zero" shows a balanced flow and a high transit function of the ecological and economic system.

Therefore, the integration of ecological and economic systems is based on the intensity of substance, energy and information flows between them. The cost method of their estimation is relatively simple based on the study of trade turnover and the cost of the remainder of unutilized waste recycling.

\section{RESULTS AND DISCUSSION}

The object of the study of exchange flows between ecological and economic systems was Penza region of the Russian Federation. The region is agro-industrial and is located in the center of the forest-steppe zone of the Eastern European Plain. In terms of physical geography, it is divided into five major districts [12]: Zasurskiy elevated forest, KadadinskoUzinskiy steeply-sloping hilly forest-steppe, Vado-Vyshinskiy low-lying forest, Vorono-Khoperskiy low-lying-elevated steppe and Sursko-Mokshanskiy elevated forest-steppe. The development of agricultural production is due to favourable agroclimatic conditions: the situation in a moderate warm climatic area of a temperate climate (according to the Kappen and Geiger classification) of moderate moisture (the hydrothermal coefficient is slightly higher than 1.1 and slightly decreases to the southwest), the sum of biologically active temperatures (temperatures above $10{ }^{\circ} \mathrm{C}$ ) exceeds $2300{ }^{\circ} \mathrm{C}$, fertile black soils and gray forest soils have been formed.

The industrial potential is due to the availability of highly qualified personnel in instrumentation and heavy engineering, the chemical industry and the military-defense complex. Extracting companies provide raw materials for the construction industry, handicrafts and glass production.

To estimate the intensity of flows between ecological and economic systems of Penza region (Table I), statistical indicators from officially published data of the Federal State Statistics Service of the Russian Federation were used [13]. The amount of current expenses on environmental protection measures (thousand rubles), the amount of emissions by economic entities (thousand tons), and the amount of pollutants captured (thousand tons) were determined.

The expenses on environmental protection among the administrative districts of Penza region in 2019 varies significantly: from 194 thousand rubles in Luninsky district to 69687 thousand rubles - in Penzensky one. The leaders in this indicator are Penzensky, Bessonovsky, Kamensky, Maloserdobinsky and Belinsky districts. This is due to the developed industrial production, electric power and extractive industries. Due to their agricultural specialization and the production of primary processing of agricultural products, such districts as Luninsky, Bekovsky and Lopatinsky spend relatively little on the waste from stationary sources recycling.

Penzensky. Bessonovsky. Gorodishchensky and Bashmakovsky districts - the largest industrial hubs in the region - are leading by volume of emissions into the environment (up to 3.3 thousand tons of emissions). The lowest amount of emissions is observed in areas with distinct agricultural specialization: in Lopatinsky. Maloserdobinsky. Tamalinsky. Mokshansky. Sosnovoborsky. Narovchatsky and Luninsky districts it is less than 0.1 thousand tons. and in Vadinsky it is less than 0.02 thousand tons. This explains the low volume of pollutants captured. From the given list of the districts of the region which are most polluted with waste from economic activities. the most pollutants are captured. A little less than 2 thousand tons in each of them.

The amount of expenses on environmental protection measures was defined as the ratio between current environmental protection expenses and the amount of pollutants captured. According to this indicator. Mokshansky. Serdobsky. Sosnovoborsky and Narovchatsky districts are in the lead; here 
the cost ranges from 31 to 43 thousand rubles. The lowest amount of expenses is in Issinsky and Vadinsky districts - 2054 rubles and 0 rubles respectively. The average cost per ton is 103993 rubles. and the median cost is 52067 rubles.

The product of the difference between the amount of emissions and the captured pollutants by the cost of environmental protection measures is the volume of expenses for the residual pollutants disposal. Of course. this remainder is not always included in the flow of exchange between ecological and economic systems. but it represents a part of it which bears environmental costs. According to this indicator. the Serdobsky district is in the lead -1007509 thousand rubles. which is due to the low amount of waste recycling. The volume of disposal expenses in Nikolsky district is three times less - about 307270 thousand rubles. In Nizhnelomovskiy. Penza and Bashmakovskiy districts. the expenses range from 106920 to 128883 thousand rubles. The lowest expenses on waste disposal in Lopatinsky and Tamalinsky districts are 2184 и 2160 thousand rubles. respectively.

Table 1. Statistical Indicators of EnVironmental Protection, Volume of Sales AND Products Sold Not OF Own Production of the ADMINISTRATIVE-TERRITORIAL DISTRICTS OF PENZA REGION IN 2019

\begin{tabular}{|c|c|c|c|c|c|c|c|c|c|}
\hline $\begin{array}{l}\text { Administrative } \\
\text { district }\end{array}$ & 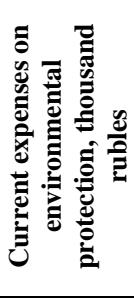 & 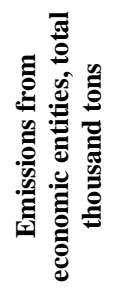 & 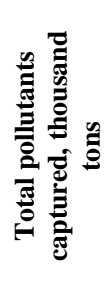 & 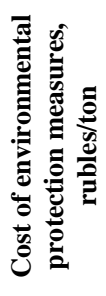 & 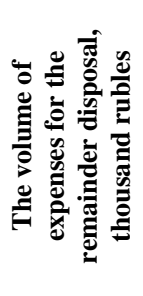 & 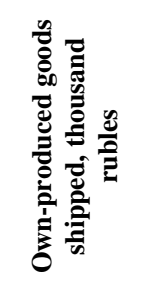 & 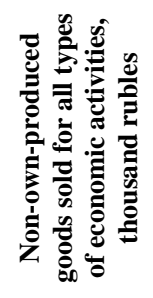 & 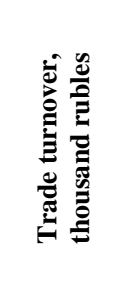 & 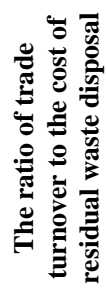 \\
\hline Bashmakovsky district & 21633 & 2.995 & 0.504 & 42923 & 106920 & 2537045.4 & 767619.9 & 1769426 & 16.55 \\
\hline Spassky district & 3218 & 0.312 & 0.092 & 34978 & 7695 & 57230.4 & 970837.6 & -913607 & -118.72 \\
\hline Bekovsky district & 621 & 0.487 & 0.013 & 47769 & 22643 & 1740017.6 & 1685044.2 & 54973.4 & 2.43 \\
\hline Belinsky district & 43208 & 0.301 & 0.263 & 164289 & 6243 & 1990476.3 & 775967.6 & 1214509 & 194.54 \\
\hline Bessonovsky district & 60803 & 3.163 & 1.995 & 30478 & 35598 & 14436308.7 & 13654776.4 & 767619.9 & 21.56 \\
\hline Vadinsky district & 2064 & 0.025 & 0 & 0 & 20643 & 93191.4 & 131617 & -38425.6 & -18.62 \\
\hline Gorodishchensky district & 24481 & 2.918 & 1.775 & 13792 & 15764 & 2729596.2 & 1243470.7 & 1486126 & 94.27 \\
\hline Zemetchinsky district & 3405 & 0.52 & 0.044 & 77386 & 36836 & 4090603.2 & 819877.9 & 3270725 & 88.79 \\
\hline Issinsky district & 953 & 1.859 & 0.464 & 2054 & 2865 & 1075602.2 & 508410.9 & 567191.3 & 197.96 \\
\hline Kamensky district & 49720 & 2.354 & 1.255 & 39618 & 43540 & 9762974.5 & 3423550.9 & 6339424 & 145.60 \\
\hline Kameshkirsky district & 3557 & 0.466 & 0.247 & 14401 & 3154 & 606900.3 & 238358.3 & 368542 & 116.86 \\
\hline Kolyshleysky district & 4367 & 0.298 & 0.113 & 38646 & 7150 & 2029448.2 & 776357.6 & 1253091 & 175.27 \\
\hline Kuznetsky district & 14665 & 0.429 & 0.238 & 61618 & 11769 & 1393402.4 & 1812339.7 & -418937 & -35.60 \\
\hline Lopatinsky district & 815 & 0.184 & 0.05 & 16300 & 2184 & 356391.7 & 277272.8 & 79118.9 & 36.22 \\
\hline Luninsky district & 194 & 0.11 & 0.002 & 97000 & 10476 & 722644.7 & 591773.1 & 130871.6 & 12.49 \\
\hline Maloserdobinsky district & 2820 & 0.169 & 0.032 & 88125 & 12073 & 421353.4 & 188250.8 & 233102.6 & 19.31 \\
\hline Mokshansky district & 24059 & 0.161 & 0.056 & 429625 & 45111 & 1370344 & 1336758.8 & 33585.2 & 0.74 \\
\hline Narovchatsky district & 21489 & 0.127 & 0.069 & 311435 & 18063 & 1543835.9 & 348607.9 & 1195228 & 66.17 \\
\hline Nizhnelomovskiy district & 28558 & 1.483 & 0.269 & 106164 & 128883 & 33179263.4 & 24766495.7 & 8412768 & 65.27 \\
\hline Nikolsky district & 31510 & 1.774 & 0.165 & 190970 & 307270 & 6706206.2 & 1209063.5 & 5497143 & 17.89 \\
\hline Pachelmsky district & 8400 & 1.012 & 0.543 & 15470 & 7255 & 1226761.8 & 509223.8 & 717538 & 98.90 \\
\hline Penzensky district & 69687 & 3.309 & 1.293 & 53896 & 108654 & 7584543.6 & 2877701.8 & 4706842 & 43.32 \\
\hline Serdobsky district & 45022 & 2.782 & 0.119 & 378336 & 1007509 & 3968894.8 & 3996102.3 & -27207.5 & -0.03 \\
\hline Sosnovoborsky district & 4813 & 0.128 & 0.013 & 370231 & 42577 & 113558.1 & 359713.9 & -246156 & -5.78 \\
\hline Tamalinsky district & 6280 & 0.168 & 0.125 & 50240 & 2160 & 1135156.6 & 813571.9 & 321584.7 & 148.86 \\
\hline Shemysheysky district & 2302 & 0.218 & 0.082 & 28073 & 3818 & 359431.2 & 449893.6 & -90462.4 & -23.69 \\
\hline
\end{tabular}


The flow of goods. raw materials. and intermediate products between ecological and economic systems is defined as the trade turnover between the value of goods. intermediate products and services produced in a given territory and the value of non-own-produced products sold for all types of economic activities. According to this indicator. the maximum values are observed in Nizhnelomovsky (8412768 thousand rubles). Kamensky (6339424 thousand rubles). Nikolsky (5497143 thousand rubles) and Penzensky districts (4706842 thousand rubles). Negative values of the indicator are typical for six districts of the region: Serdobsky. Vadinsky. Shemysheysky. Sosnovoborsky. Kuznetsky and Spassky.

As a result. the ratio of trade turnover to the residual waste disposal costs characterizes the flow between ecological and economic systems. Related to the sign of the trade turnover indicator. the value can be positive. negative. or tend to "zero".

The value of the ration of trade turnover to the residual waste disposal costs approaches "zero" only in Mokshansky. Serdobsky. Vadinsky and Bekovsky districts. The spread of the coefficient is large: from -118.72 in the Spassky district to 197.96 in Issinsky. For the convenience of analysis. all districts of the region are divided into three groups with an equal interval of 105.56 : from -118.72 to -13.16 ; -13.16 to 92.4 ; from 92.4 to 197.96. Using the geographic information program SagaGIS 7.7.0 a map of the ratio value in the administrative districts of the region is constructed (Fig. 1). The main number of districts is characterized by an average ratio of 15 administrative areas. 8 districts are marked with a small amount of expenses for the residual waste disposal to trade turnover: Issinsky. Belinsky. Kolyshleisky. Tamalinsky. Kamensky. Kameshkirsky. Pachelmsky and Gorodishchensky.

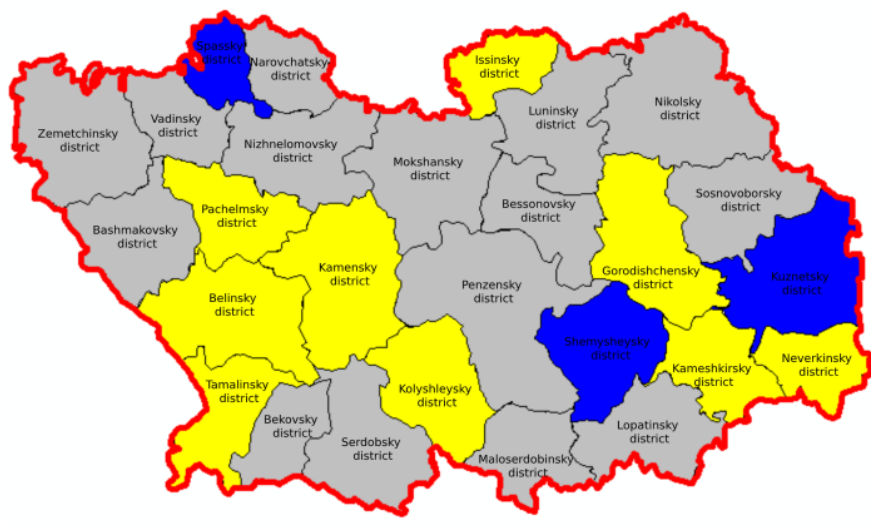

Fig. 1. Map of the ratio of trade turnover to the cost of residual waste disposal in the districts of Penza region in 2019 : blue $-(-118.72 ;-13.16)$. grey $-(-13.16$; 92.4). yellow - $(92.4 ; 197.96)$

Therefore. there is a noticeable connection between the level of recycling development in the economies of administrative districts of Penza region and the accumulation of unprocessed waste residues in their ecological and economic systems. This does not mean that agricultural organizations do not pollute natural systems. The methodology of statistical research simply does not cover them.

Despite the fact that in general the ecological and economic systems of Penza region produce much more than they emit waste. they are all transit. The most important transport routes pass through their territory: the M5 "Ural". R-208 "Penza Tambov". R-158 "Nizhny Novgorod - Saratov", the largest railway junction of the main communications of the Kuibyshev Railway.

\section{CONCLUSION}

The research on the transit of substance. energy. and information flows in ecological and economic systems has shown that:

1) One of the intensity indicators of flows between ecological and economic systems is the ratio between trade turnover and the cost of residual waste disposal. The close-tozero ratio shows a balanced flow and a high transit function of the ecological and economic system.

2) Low expenses on the industrial waste recycling are the reason for the increased values of the ratio in the administrative districts of Penza region. This is due to their agricultural specialization and transit position.

3) The most industrialized areas have high values of waste emissions. but also a significant amount of recycling. as well as the cost of existing emissions disposal.

The proposed intensity coefficient of substances transit is limited in use and does not fully reveal the facets of integration between ecological and economic systems. which requires further research in this area.

\section{Acknowledgment}

This work was supported by the Russian Foundation for Basic Research (project no. 20-010-00875 A, Problems of management of sustainable socio-ecological and economic development of Russia and ways to solve them).

\section{References}

[1] I. Røpke, "Ecological Macroeconomics: Implications for the Roles of Consumer-Citizens. Innovations in Sustainable Consumption: New Economics", Socio-technical Transitions and Social Practices, 2013, vol. 3, pp. 48-64. DOI: 10.4337/9781781001349.00012

[2] R. Costanza, "What is Ecological Economics?", Ecological Economics, 1989, vol. 1(1), pp. 1-7. DOI: 10.1016/0921-8009(89)90020-7.

[3] R. Costanza, Ecological Economics: The Science and Management of Sustainability, Columbia University Press, New York ed., 1991.

[4] B. Fu, G. Liu, L. Chen, K. Ma, and J. Li, "Scheme of Ecological Rregionalization in China", Acta Ecologica Sinica, 2001, vol. 21(1), pp. $1-6$.

[5] Q. Gao, and H. Mao, "GIS-Based Study on the Ecological and Economic Regionalization of Yun-Yang County in the Three Gorges Reservoir Area", Acta Ecologica Sinica, 2003, vol. 23 (1), pp. 74-81.

[6] C. Cavalcanti, "Conceptions of Ecological Economics: Its Relationship with Mainstream and Environmental Economics", Estudos Avançados, 2010, vol. 24(68), pp. 53-67.

[7] K.J. Arrrow, and A.C. Fisher, "Environmental Preservation. Uncertainty. and Irreversibility", The Quarterly Journal of Economics. Oxford University Press, 1974, vol. 88(20), pp. 312-319.

[8] Y.J. Ahmad, S.El. Sefary, and E. Lutz, Environmental Accounting for Sustainable Development (UNEP-World Bank Symposium). The World Bank, Washington DC, 1989, $112 \mathrm{p}$

[9] M. Barber, B. Patren, and J. Finn, "Review and Evaluation of I-0 Flow Analysis for Ecological Applications". in: J. Matis, B. Patten, and G. White, Statistical Ecology. Compartmental Analysis of Ecosystem Models, International Cooperative Publishing House, Bertonsville MD 1979, vol. 10 .

[10] A. Munro, "Economics and biological evolution. Environmental and Resource Economics", Springer, 1997, vol. 9(4), pp. 429-449. DOI: 10.1007/BF02441760 
[11] A.L. Aleksandrovskii, E.I. Aleksandrovskaya, I.V. Zamotaev, and A.N. Kurbatova, "Soils and cultural layers of ancient cities in the south of European Russia", Eurasian Soil Science, 2015, vol. 48(11), pp. 11711181. DOI: $10.1134 / \mathrm{S} 1064229315110022$
[12] I.I. Kurizin, and N.A. Mardensky, Geography of the Penza region, Penza, 1991, pp. 32-36

[13] Federal State Statistics Service of the Russian Federation, 2020. Retrieved from https://rosstat.gov.ru/ 